\title{
AC 2007-588: PROFICIENCY EXAMS IN A SUPPORTIVE LEARNING ENVIRONMENT
}

\section{William Carpenter, University of South Florida}

William Carpenter is a Professor in the Civil and Environmental Engineering Department at the University of South Florida. He received his B.S. and Ph.D. from NC State University, has 6 years of industrial experience with Boeing and consulting engineering companies, and has been affiliated with several universities in the U.S. and Europe. 


\section{A Proficiency Exam Protocol in a Supportive Learning Environment}

\section{Introduction}

A procedure utilizing proficiency exams, referred to as The Proficiency Exam Protocol, was developed by this author and was found to be a powerful way to help students learn material, build their skill sets, and develop cognitively. The Proficiency Exam Protocol is more effective and less stressful to students than homework, exams, and pop quizzes. The Proficiency Exam Protocol leads to enhanced student cognitive development and guarantees that students have a mastery of basic material. Not only does The Proficiency Exam Protocol help students learn, it also provides an assessment method which assures satisfaction of specific ABET outcomes.

\section{The Proficiency Exam Protocol}

The format of The Proficiency Exam Protocol is as follows:

- A topic is presented to students using traditional teaching techniques: lecturing, active learning, cooperative learning, homework, etc. (As an example, one topic covered in Structures I is bar forces in a truss using the Method of Joints.)

- After the coverage of this topic, students are given a single exam question on the topic where they can demonstrate proficiency. (In the Structures I example, the exam question would require that students solve for all the bar forces in a simple truss as shown in Figure 1.)

- Although proficiency can be defined in numerous ways, the method works well when, to demonstrate proficiency, a student's solution must be $100 \%$ correct. This definition of proficiency forces students to thoroughly understand material, eliminates student attempts to negotiate for a better part-score, and makes it much easier to grade the proficiency exams.

- Unless calculations are done to engineering graphics standards and are organized so that they can be readily checked, the exam is not even graded. Thus, the proficiency exams become not only a way of ensuring that students have mastered material but are also used to help develop students' organizational and communication skills.

- In order to relieve test anxiety and the stress caused by the demanding grading scheme, students are allowed to take, without penalty, as many proficiency exams on a topic as are required to demonstrate proficiency.

- The initial administration of a proficiency exam occurs in the classroom.

- Subsequent administrations require students to come to the professor's office to take a re-exam or arrangements are made for a group of students to take a reexam after class. Therefore, remake proficiency exams do not impinge on class time.

- After 2 or 3 failed attempts to demonstrate proficiency, a student is not allowed to take further exams until he/she comes to the professor's office so that the professor has the opportunity to work one-on-one with the student on his/her comprehension of material. 
- In the extreme case where a student can not pass the exam after repeated attempts, the professor requires the student to be present while the student's exam is graded. The professor then points out to the student mistakes, asks relevant questions to ensure comprehension of material, and then has the student rework the exam; or

- The student works the proficiency exam while the professor watches so that the professor can point out errors as they occur and have the student immediately correct them.

- Students are not expected to demonstrate complete mastery of every topic covered in a course. However for those topics in which mastery is required, in order to pass the course, students must pass a proficiency exam on each of those topics. For example, in order to pass Structures I, students must pass proficiency exams on the following topics:

Bar forces in a simple truss,

Bar forces in a complex truss,

Shear and bending moment diagrams for a simple beam problem, and

Shear and bending moment diagram for a complex beam problem.

The above topics were selected because students were exposed to the topics in earlier courses and a great deal of class effort was directed towards the topics in Structures I. Therefore in these specific topics, mastery was expected and required. In the case of new material where students had had a limited amount of time to process the material or when material was not covered in depth, expecting complete mastery of the material was not considered reasonable.

- The Proficiency Exam Protocol is useful in assuring that students have mastered essential basic material. It is not useful in assigning course grades. In courses where The Proficiency Exam Protocol has been used, course grades were assigned based on a weighted score of homework, projects, and standard examinations.

Find the bar forces in all the members of the truss. Indicate whether members are in tension or compression.

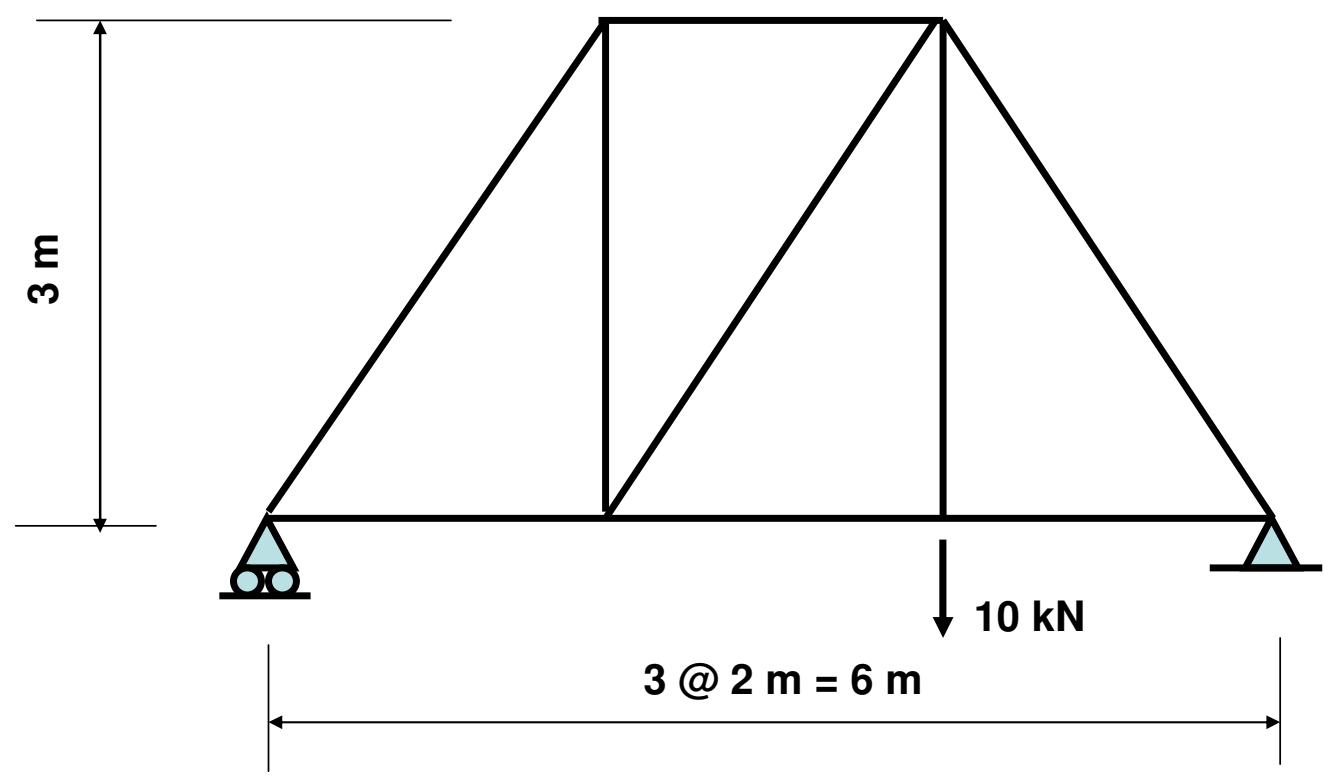

Figure 1. Bar forces in a truss proficiency exam 


\section{How the Use of The Proficiency Exam Protocol Started at USF}

The Proficiency Exam Protocol was initially used to remediate poorly prepared students. Prior to 2002, the Department of Civil Engineering at the University of South Florida employed adjuncts to teach the majority of its Statics and Mechanics of Materials courses. Some of these adjuncts were failing to adequately prepare students in required material. In 2002, the author taught the next course in the curriculum sequence, Structures $I$, and was appalled to discover how little the students knew of the material presented in the earlier courses in the sequence. The teaching challenge was how to increase student competence in a number of topics to the appropriate level of proficiency without expending a great deal of class time on actual remediation. The approach followed was to briefly review the most important topics from Statics and Mechanics of Materials and then to employ The Proficiency Exam Protocol in order to ensure that students had a true mastery of the material. Indeed, the use of The Proficiency Exam Protocol worked quite well in this remediation effort. Subsequently, the author discovered that, whenever basic material is taught, The Proficiency Exam Protocol can be a powerful aid to student learning and has used the approach in Mechanics of Materials, Structures I, and Numerical and Computer Tools in Engineering.

\section{Assessment of the Effectiveness of The Proficiency Exam Protocol}

The Proficiency Exam Protocol has been found to be an extremely effective tool in enhancing student learning. Results are presented based on a survey given to 70 students taking Structures I in Semester II, 2005. In this survey in which 59 students responded, students rated the following activities as to their effectiveness as a learning tool:

- The Proficiency Exam Protocol (PEP),

- Homework checked for completion but not graded $(H C)$,

- Homework that is graded $(H G)$,

- Quizzes $(Q)$,

- Quizzes where a remake quiz is allowed $(Q R)$, and

- Pop Quizzes $(P Q)$

The Student's t test ${ }^{1}$ was applied to the data from this survey. When comparing two learning tools, this paper follows the standard statistical convention that:

- "Low statistical significance" denotes that there is less than a 95\% chance of the means being significantly different.

- "Significant " denotes that there is a $95 \%$ or better chance of the means being significantly different.

- "Highly significant" denotes that there is a $99 \%$ or better chance of the means being significantly different.

- "Very highly significant" denotes that there is a $99.9 \%$ or better chance of the means being significantly different.

Survey results, shown in Figure 2, are next discussed:

\section{$P E P$ compared to $\mathrm{HC}$ and $\mathrm{HG}$}

The Student's t test indicates that the difference between the $P E P$ rating and the $H C$ rating is very highly significant and the difference between the $P E P$ rating and $H G$ is 
highly significant. One can see in Figure 2 that The Proficiency Exam Protocol was rated better than homework, either checked or graded. It is not surprising that un-graded homework is rated poorly as no feedback is given to students. However even when homework is graded, homework is not rated as highly as The Proficiency Exam Protocol. It appears that for effective student learning, not only does a professor need to give feedback but must also require students to process that feedback as with The Proficiency Exam Protocol.

\section{$P E P$ compared to $Q$ and $P Q$}

The Student's t test indicates that differences between the mean of the PEP rating and the mean of the $Q$ rating and the mean of the $P Q$ rating are very highly significant. Quizzes with no remakes and pop quizzes give feedback but do not require that the feedback be processed. One can see in Figure 2 that they are not rated as highly as The Proficiency Exam Protocol.

\section{$P E P$ compared to $Q R$}

The Student's t test indicates that there is low statistical significance between the means of the $P E P$ rating and the $Q R$ rating. Quizzes, where there is a remake permitted, force students to process feedback from the first quiz as does The Proficiency Exam Protocol. Both of these schemes were rated highly. By rating highly both tools, it seems that students appreciate the importance of both feedback and the need to process it.

\section{The Proficiency Exam Protocol Learning Tool Rating}

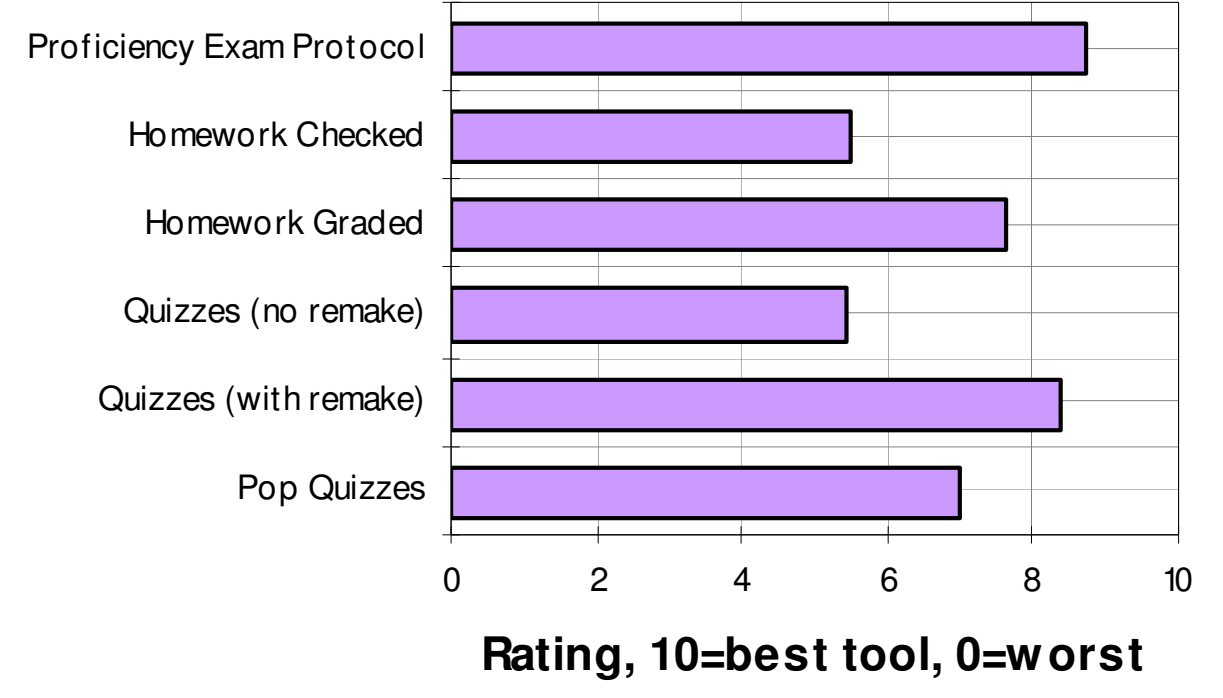

Figure 2. Student Rating of Learning Tools 
A positive feature of The Proficiency Exam Protocol is that it forces students to learn without producing high student anxiety. Students in Structures I were asked to rate how much anxiety was produced by various teaching tools. The results of this survey are shown in Figure 3. The Student's t test indicates that the difference between the mean of PEP and the mean of the other learning tools is as follows:

- $\quad P E P$ and $H C$, very highly significant

- $P E P$ and $H G$, low statistical significance

- $\mathrm{P} E P$ and $Q$, very highly significant

- $\quad P E P$ and $Q R$, low statistical significance

- $\quad \mathrm{P} E P$ and $P Q$, significant

These results indicate that there is little difference between the anxiety caused by the Proficiency Exam Protocol, Graded Homework, and Quizzes (with remakes) while The Proficiency Exam Protocol gives significantly less anxiety than quizzes (no remakes) and pop quizzes.

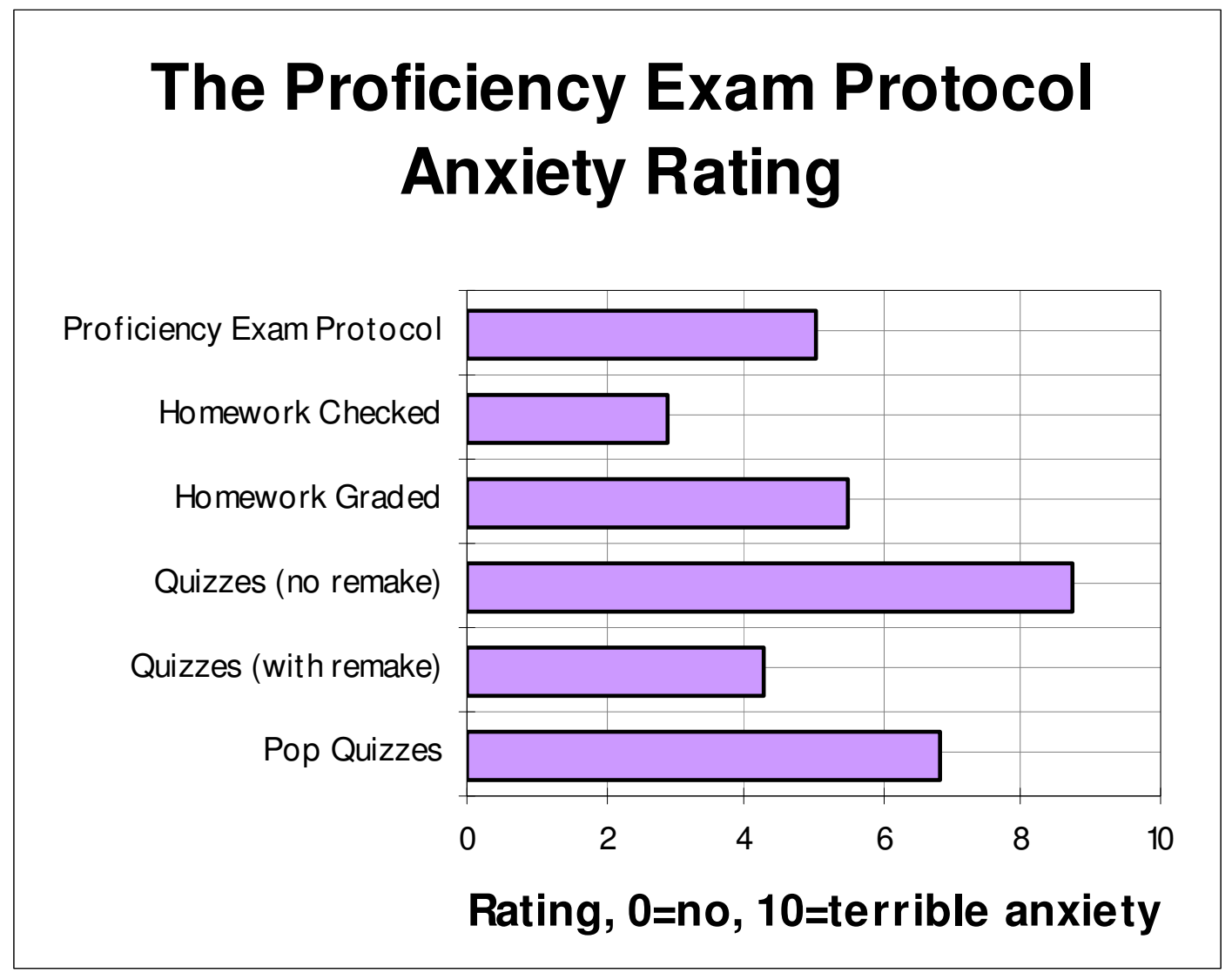

Figure 3. Anxiety Rating of The Proficiency Exam Protocol and Other Activities 
After completing courses which utilize The Proficiency Exam Protocol, students report that they feel competent in the material covered by the proficiency exams. Students in Structures I were tested throughout the course using The Proficiency Exam Protocol on a number of topics (bar forces in simple and complex trusses and shear and bending moment diagrams of various degrees of difficulty) which had previously been introduced in the pre-requisite courses Statics and Mechanics of Materials. However, many students enrolling in Structures I do not have mastery of these topics. Upon completion of Structures I, students were asked to rate how well they knew this material at various stages of their academic program. Results are shown in Figure 4. One can see in Figure 4 that while many students felt that they did not have mastery of the material covered by the proficiency exams when first enrolled in Structures I, most felt that they had mastery of the material at the end of the course. Of course, one can not say that this increase in mastery of material was entirely the result of The Proficiency Exam Protocol, but the results of Figure 4 coupled with other assessment results and student written comments suggests that The Proficiency Exam Protocol had a very positive effect in increasing student mastery of material.

\section{Structures I Topics Knowledge Rating}

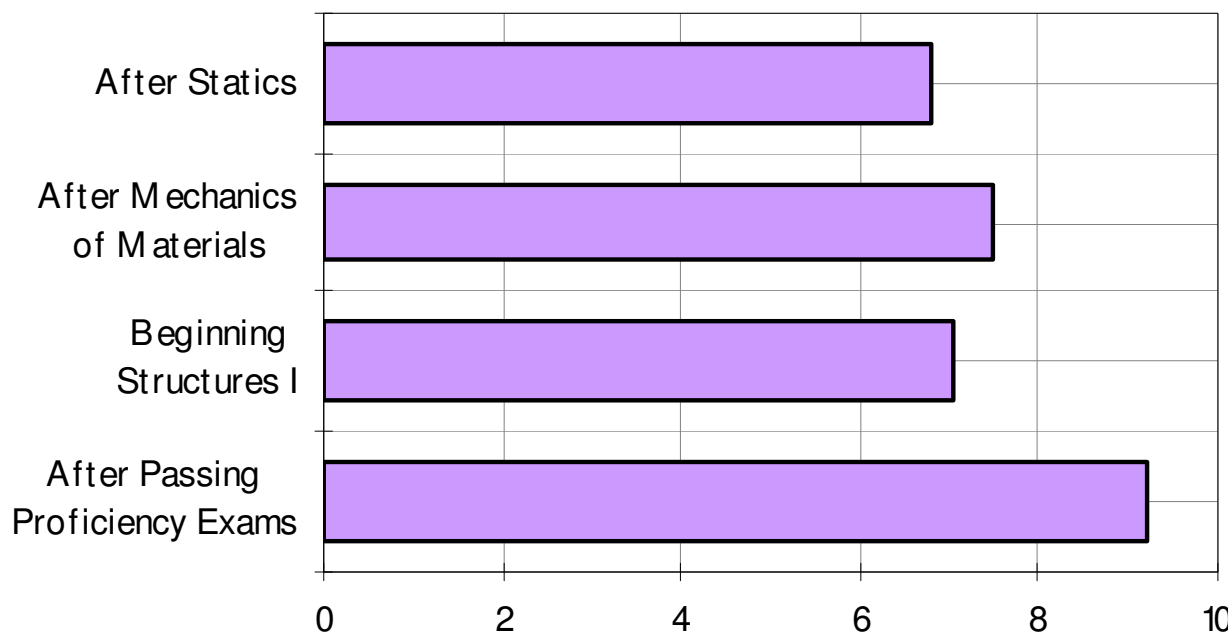

$0=$ no knowledge, 10=know well

Figure 4. Student perception of how well they know proficiency exam material 
An additional positive feature of The Proficiency Exam Protocol is that students appear to like the approach. Students in Structures I were asked whether they would recommend The Proficiency Exam Protocol for Structures I and for the two pre-requisite courses Statics and Mechanics of Materials. Results are shown in Figure 5. Over 90\% recommended its use in Structures I and over $80 \%$ recommended its use in the prerequisite courses.

The Proficiency Exam Protocol requires some effort on the part of the instructor and the students. Students were asked if the protocol was worth the effort required. One can see in Figure 5 that approximately $90 \%$ of students thought that the use of The Proficiency Exam Protocol was worth the effort. In Structures I, a proficiency exam was given a grade of pass if the solution was absolutely correct. Otherwise, the exam was given a grade of fail. Students were asked to evaluate this grading scheme. One can see in Figure 5 (under the heading Grade Pass/Fail) that approximately 80\% agreed with this grading scheme. Students who disagreed with the scheme were mainly those students who thought that minor mistakes should be overlooked.

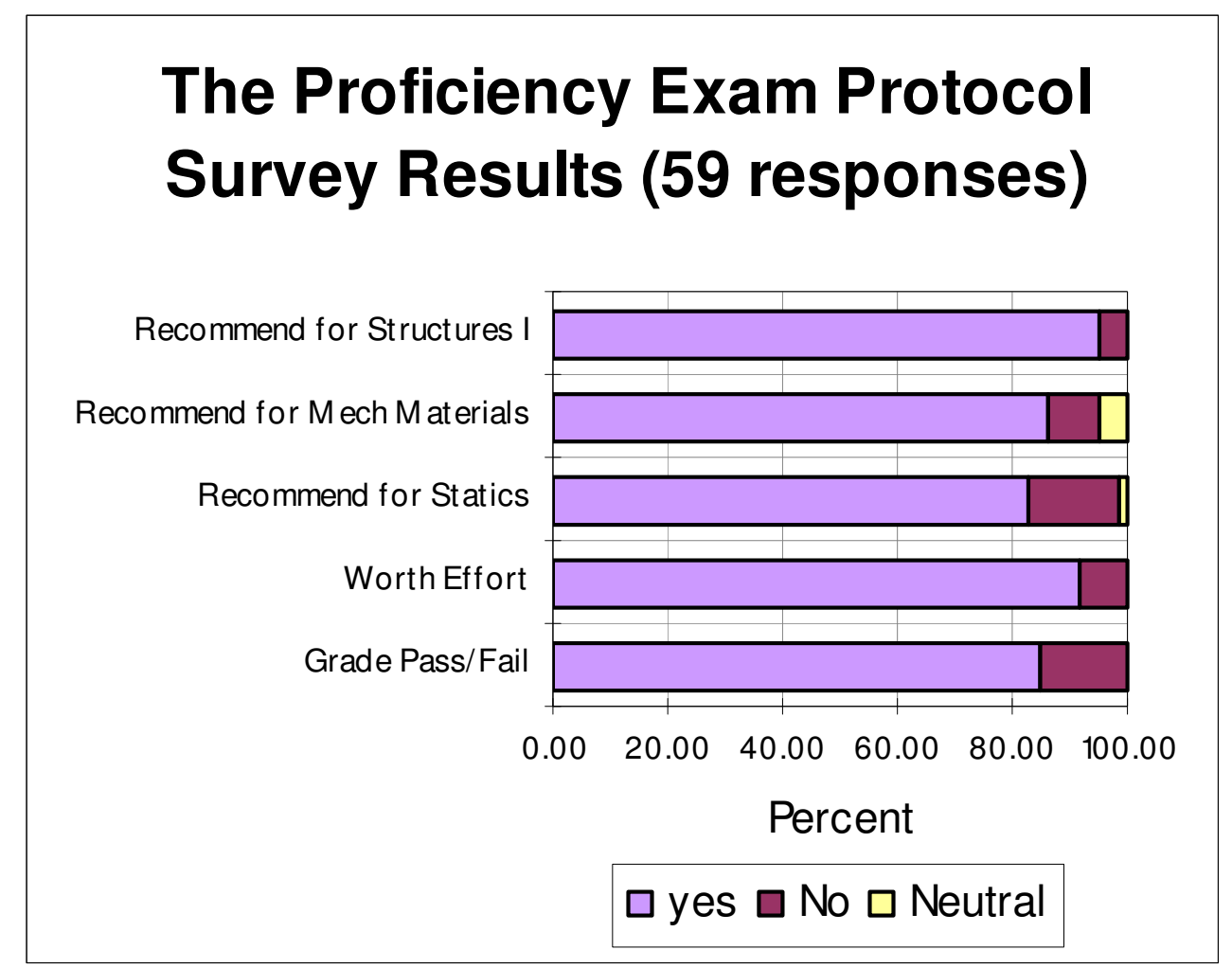

Figure 5. Student Approval of The Proficiency Exam Protocol 
Student comments on the Structures I course assessment indicate that students like The Proficiency Exam Protocol. As part of the course assessment of Structures I, students are given the opportunity to write comments concerning The Proficiency Exam Protocol. Below are all of the written student comments from a 2003 assessment of Structures I in response to the question Do you feel that The Proficiency Exam Protocol was worth the effort that the class and instructor had to put into it?

- "Definitely!!"

- "It reinforces the key objectives of the class"

- You forced us to learn basics"

- Yes, they force you to learn basic bench marks in structures design"

- "We wasted a lot of time doing the proficiency exam"

- "Makes an individual learn the basic concepts of the course"

- "Best thing in the class"

- "We need to know exactly how to solve these problems, and you stressed that."

One can see that the comments are overwhelmingly positive. The one negative comment may have been from the same student who asked me "Why don't you just let us make mistakes?" which might be translated to mean "Learning the basics and developing cognitively takes work that I don't want to put into the course. Just give me a C grade and let me go."

There are some external results to support the use of The Proficiency Exam Protocol. In 2001, the Assessment Committee of the Civil and Environmental Engineering Department at USF reviewed student performance on the Fundamentals of Engineering Exam. The committee considered data from 5 examinations in the 1997-1999 time period. The committee computed the parameter Department \% passing less nation \% passing for topics covered in both the morning general examination and the afternoon general examination and also for topics covered in the afternoon discipline specific examination.

Based on this study, the committee recommended that the Department take actions to try to improve student performance on the FE exam. Because of this recommendation, the Department discontinued the use of adjuncts to teach Statics, Mechanics of Materials, and Structures I. It also added a weekly problem session to Statics and Mechanics of Materials and this author started teaching Structures I and incorporated The Proficiency Exam Protocol into that course.

The Assessment Committee reviewed again student performance on the FE exam using data from 4 examinations in the 2004-2005 time period. The following improvements in the parameter Department \% passing less nation \% passing were found:

- Statics-3\%

- Mechanics of Materials-4\%

- Structural Analysis-4\%

Since the application of The Proficiency Exam Protocol in Structures I requires mastery of topics from statics and mechanics of materials, one would expect that The Proficiency 
Exam Protocol would improve student results in statics and mechanics of materials as well as in structural analysis. This indeed was found to be the case. Of course, actions other than the use of The Proficiency Exam Protocol in Structures I were undertaken by the Department between 2001 and 2004 so the improvement in scores can not be solely attributed to the Protocol. However, it seems reasonable to assume that some of the improvement could have resulted from The Proficiency Exam Protocol.

\section{Manpower Requirements to Conduct The Proficiency Exam Protocol}

The Proficiency Exam Protocol outlined can be carried out in a reasonable amount of time. Although it might seem that this process would be very demanding of a professor's time, this is not the case for the following reasons:

- It takes minimal time to make up a single question proficiency exam. Remake exams can be created simply by changing dimensions or loads.

- When exams are graded as either $100 \%$ correct or not $100 \%$ correct, it takes very little time to grade a proficiency exam. When a grader sees any mistake, the grader simply stops grading the exam.

- Most students demonstrate proficiency on a topic in one or two attempts. Therefore, the number of remake exams that have to be graded is not large.

One of the more time-consuming activities associated with The Proficiency Exam Protocol involves working with students one-on-one when they fail after 2 or 3 attempts to demonstrate proficiency in a topic. With the protocol, before a student is allowed to retake another proficiency exam, the student must work with the instructor to ensure that he/she comprehends the material. In an extreme case, a student may have to take a proficiency exam while the instructor is watching and pointing out errors before he/she begins to understand the exam material. Figure 6 shows the cumulative pass rate of students on proficiency exams in a section of Structures I. One can see in Figure 6 that all students in this section demonstrated proficiency on all topics after 4 attempts. This success occurred because the weaker students had worked one-on-one with the instructor before their $4^{\text {th }}$ exam attempt.

The amount of effort expended by the instructor on this one-on-one effort is not prohibitive. With classes of 70 or 80 students, the author typically spends no more than 2 or 3 hours a week in one-on-one instruction, with the peak effort occurring during the last 3 or 4 weeks of a semester when students are trying to complete their proficiency requirements. The author has found that this one-on-one effort is very rewarding in that the students who receive individual attention are usually the students who, without this attention, would fail the course or would at best make a $\mathrm{D}$ or $\mathrm{C}$ grade by getting part scores on exam questions. Before employing The Proficiency Exam Protocol, the author saw numbers of students pass his classes without ever having answered a single question absolutely correctly. The author's desire to eliminate such an occurrence is one of the motivating factors that caused him to initiate The Proficiency Exam Protocol as a teaching strategy. 


\section{Culmulative Pass Rate Structures I Proficiency Exams}

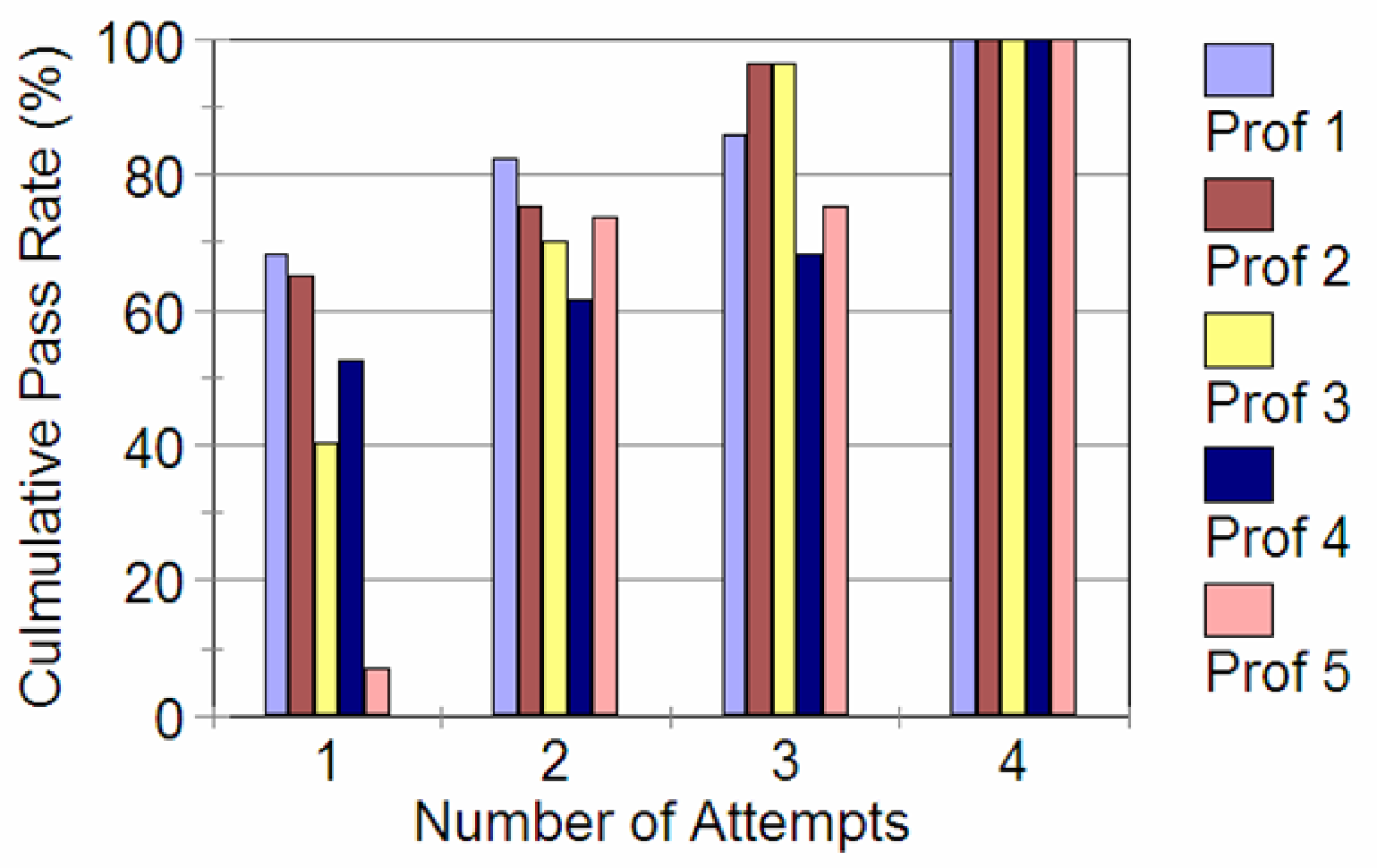

Figure 6. Number of Attempts to Demonstrate Proficiency

Promoting Student Intellectual Development with The Proficiency Exam Protocol The Proficiency Exam Protocol is an excellent way to promote student cognitive development. Bloom and his co-workers ${ }^{2}$ defined six levels of cognitive development

- Knowledge

- Comprehension

- Application

- Analysis

- Synthesis

- Evaluation

Engineers solve engineering problems by applying concepts and principles from mathematics, science, and engineering science. Thus at a minimum, they must be functioning at the Application level of cognitive development. Many students in early engineering science courses such as Statics, Dynamics, and Mechanics of Material and in early engineering courses such as Structures I are still functioning at the Comprehension Level (i.e. they do not completely understand underlying concepts) or are not fully functioning at the Application level; namely, they do not completely understand how to apply principles and concepts, are not capable of working with precision, do not have the 
organizational shills to break complicated problems into manageable sub-problems, or their calculations are so poorly presented and disorganized that they can not even follow their own work. One of the challenges faced by educators in these early courses is to force students to function at the Application level of cognitive development. ABET recognizes that graduates need to be able to function at this level. ABET "Outcome $a$ " states that engineering graduates must have an ability to apply knowledge of mathematics, science, and engineering ${ }^{3}$ indicating that upon graduation students need to be functioning at the Application level of cognitive development.

The Basic Level Civil Engineering Program Criteria has been formulated by the Accreditation Subcommittee of the ASCE Committee on Academic Prerequisites for Professional Practice. The criteria has been submitted for ABET approval. Upon final approval from ABET, the criteria will be implemented in accreditation visits beginning in 2008. In this new criteria, the Civil Engineering requirement for proficiency in four areas of Civil Engineering has been replaced with provisions that use the verb apply. Thus, the new criteria more strongly emphasizes that graduates must be upon graduation, at the minimum, at a cognitive level of Application ${ }^{4}$.

The Proficiency Exam Protocol outlined is an ideal approach for raising students to the Application level of cognitive development. Students can only pass a proficiency exam if they understand the underlying concepts and principles of course material, have organizational skills, and are able to apply these concepts and principles to the problem at hand. With traditional grading schemes, students may even graduate without functioning completely at the Application Level of cognitive development or perhaps not even functioning completely at the Comprehension level. Because of the grading rubric used in a course or because grades are assigned using a curve, some students may receive passing grades without completely understanding basic underlying concepts and principles and/or without being able to apply concepts and principles to problems in the course. Thus, course grades may be used as necessary conditions for assuring students are functioning at a given cognitive level, but do not provide sufficient condition for this assurance. When a student has passed a course utilizing The Proficiency Exam Protocol outlined, one can have much more confidence that the student is functioning at the Application level of cognitive development.

\section{The Proficiency Exam Protocol as an Assessment Tool}

The Accreditation Board for Engineering and Technology in its Criteria 3 specifies that students meet the a-k Student Outcomes ${ }^{3}$. These outcomes are the accomplishments expected of graduates. ABET does not specify the assessment tools to be used in order to verify that graduates meet these outcomes. Thus, how to assess each of the a-k outcomes is a dilemma faced by the academic community. The Proficiency Exam Protocol outlined is an excellent way of ensuring that graduates have satisfied student Outcome a which states that engineering graduates have an ability to apply knowledge of mathematics, science, and engineering. Also, if The Basic Level Civil Engineering Program Criteria is approved by ABET and becomes effective beginning in 2008, proficiency exams may be 
a good way to assess whether students can apply engineering knowledge to solve problems in 4 areas of Civil Engineering.

\section{Conclusion}

The Proficiency Exam Protocol has been developed to provide a tool to ensure students' mastery of basic material. Student assessment of the protocol indicates that as a learning tool it is superior to homework, exams, and pop quizzes while also reducing student anxiety. The approach is very popular with students who rate the approach highly and recommend its use in other courses. The Proficiency Exam Protocol can be used as a vehicle for ensuring that students can solve engineering problems by applying concepts and principles from mathematics, science, and engineering science. Using Bloom's terminology, it can be used to ensure that students can function at the Application level of cognitive development. The Proficiency Exam Protocol can also be an effective means of ABET related assessment.

Biographical Information

1 http://helios.bto.ed.ac.uk/bto/statistics/tress4a.html

2 Taxonomy of Educational Objectives, B. S. Bloom, ed., David McKay Company, New York (1956).

3 Criteria for Accrediting Engineering Program, ABET Engineering Accreditation Commission, ABET Inc., 111 Market Place, Suite 1050, Baltimore, MD 21202 (2006).

4 Stephen J. Ressler, New Civil Engineering Program Criteria, Directions, A Newsletter of the American Society of Civil Engineers' Committee on Curricula \& Accreditation, p. 6-10 (Fall, 2006). 